\title{
Cardiovascular Risk in Patients who go to the Medical Office of a Private Health Center in North Lima
}

\author{
Jairo Zegarra-Apaza ${ }^{1}$, Sara Oliveros-Huerta ${ }^{1}$, Santiago Vilela-Cruz ${ }^{1}$, Rosita Chero-Benites ${ }^{1}$, Gissett Marcelo-Ruiz ${ }^{1}$, Leslie Yelina
} Herrera-Nolasco ${ }^{1}$, Brian Meneses-Claudio ${ }^{2}$, Hernan Matta-Solis ${ }^{1, *}$, Eduardo Matta-Solis ${ }^{3}$

${ }^{1}$ Faculty of Health Sciences, Universidad de Ciencias y Humanidades, 15314, Lima-Perú

${ }^{2}$ Image Processing Research Laboratory (INTI-Lab), Universidad de Ciencias y Humanidades, 15314, Lima-Perú

${ }^{3}$ Health Sciences, Instituto Peruano de Salud Familiar, 15304, Lima-Perú

\begin{tabular}{l} 
A R T I C L E I N F O \\
\hline Article history: \\
Received: 03 August, 2020 \\
Accepted: 12 January, 2021 \\
Online: 30 January, 2021 \\
\hline Keywords: \\
Adolescents \\
Quality of life \\
Students \\
Health \\
Adolescent psychology \\
\end{tabular}

A B S T R A C T
Cardiovascular diseases are the group of conditions produced in the heart or blood vessels.
This is one of the main causes of death in Peru and the world, produced mostly by non-
communicable diseases and harmful habits, which makes it an extremely predictable disease.
These factors include body mass index, smoking, diabetes, age, blood pressure, total
cholesterol, and high-density lipoproteins. Therefore, this study aims to identify patients who
go to the medical office of a private health center in North Lima who do not have a prior
history of a cardiovascular accident, using the cardiovascular risk calculator provided by
the Organization World Health. The present research work had a quantitative, non-
experimental, descriptive, and cross-sectional approach, in a population of 99 adult and
elderly patients. Regarding the results, it was found that $46.5 \%$ presented a low
cardiovascular risk, $37.4 \%$ a moderate risk, $11.1 \%$ a high risk and $5.1 \%$ an extremely high
risk. The information found contrasts with the number of deaths caused by this disease and
may be an indicator of greater prevention by populations with higher economic income.
Finally, it is concluded that diabetes, smoking and the age group are predisposing factors to
an increased cardiovascular risk.

\section{Introduction}

Cardiovascular risk is specified as the probability of a heart or blood vessel condition occurring [1]. The origin of cardiovascular diseases (CVD) is closely linked to harmful habits or noncommunicable diseases, from which derives its progressive and highly predictable nature [2].

According to the Framingham Heart Study, conducted from 1948 to the present, the main predictors of a CVD are age, body mass index, HDL and total cholesterol, smoking, diabetes, and treated high systolic blood pressure or untreated [3], [4]. Therefore, these predictors are also connected to illnesses and harmful habits, present and increasing mainly in developed and developing countries.

In Peru, according to data collected by the Instituto Nacional de Estadística e Informática (INEI), from 2015 to 2018 the Peruvian population has had an annual increase in cases with high blood pressure $(14.8 \%)$, diabetes mellitus $(3.9 \%)$ and obesity

\footnotetext{
${ }^{*}$ Corresponding Author: Hernan Matta-Solis, Mr., +51 1999751065 \& hmatta@uch.edu.pe

www.astesj.com
}

https://dx.doi.org/10.25046/aj060168
$(23 \%)$, which are mainly concentrated in Lima, while cases of overweight $(37 \%)$, cigarette consumption (19\%) and daily cigarette consumption (1.7\%) make up almost constant in the years of study [5]. Likewise, its importance in relation to cardiovascular risk (CVR), death attributed to diabetes also increased [6], which gives an indication of inefficient control of the disease. Consequently, as mentioned above, each year the cardiovascular disease (CVD) threat is amplified and the people with the longest longevity are affected.

On the other hand, in [7], a study was carried out in Peruvian youth and adults between 20 and 59 years old who were users of popular dining rooms, these premises being focused on food supply in areas of poverty and extreme poverty. The research found a prevalence of abdominal obesity (51.6\%), low HD-C (42.2\%), hypertriglyceridemia (35.3\%), overweight (35.8\%), high blood pressure $(21.0 \%)$ and hyperglycemia $(14.1 \%)$, thus conforming an overall metabolic syndrome of $40.1 \%$. This not only allows to infer that the state of this type of population makes them prone to CVD, but also without a preventive measure that takes an active role in the search for these patients, the risk will 
probably not be reduced until they are close to suffering a condition of this type, because despite having insurance focused on low-income populations, regular visits in search of prevention are not usually integrated in Peru.

In the study [8], carried out in a public hospital for internal medicine inpatients, vascular age and cardiovascular risk were evaluated in 238 participants who were between 30 and 74 years old without previous cardiovascular events. The objective was to determine these variables as well as the predominant risk factor. This study concluded with a medium and high cardiovascular risk in the highest percentage of the population, a difference between chronological and vascular age of 6.9 years old, and finally, diabetes and male sex were identified as predominant factors.

According [9], a research carried out in Spain, they were able to note that heart disease is the main cause of morbidity in a tertiary hospital and men between 50 and 60 years old are the ones with the highest morbidity in this pathology, causing high rates of incapacity for work, in addition the problem goes beyond the hospital setting because these patients will require cardiac rehabilitation. They also point out that emphasis should be placed on prevention, since studies have documented that of the patients who were discharged, $75 \%$ of patients re-entered for any cardiac complication.

In [10], a study was carried out in an educational institution of 100 schoolchildren from 10 to 19 years old, with the aim of determining cardiovascular risk. The study found a prevalence of cardiovascular risk of $84.6 \%$ in adolescents (15-18 years old), as well as that the consumption of alcoholic beverages and unhealthy eating habits are related to the increase in cardiovascular risk. So, it is suggested that prevention from an early age is essential to reduce its appearance in more advanced stages of life.

The objective of this research work is to identify cardiovascular risk in patients with no prior history of CVD, excluding hypertension in untreated cases, and who go to a cardiology office in a private health center, using a calculator provided by the Organization. Pan American Health (PAHO). Because of having an alteration in the cardiovascular system that is not a serious alteration, patients of the cardiology service are one of the groups to be suspected of having a cardiovascular condition that may cause irreversible damage or death of the patient.

The instrument used in this study is the CVR calculator provided by PAHO, based on a form proposed by the World Health Organization (WHO) to evaluate CVR in Latin American and Caribbean countries [11]. This instrument uses a risk score that is based on the Framingham study, which also is adapted to the characteristics of the region and these data will be processed in matrix form by the IBM SPSS statistics 25 program. This application deals with to assess CVR quickly and easily in patients, which is mainly focused as an aid to medical health personnel, but due to the simplicity of its use, this can be a great option for the recruitment of risk patients who are in areas that are difficult to access or that lack medical personnel.

The organization of the work carried out is structured in the following way: in Section II, the development carried out for the identification of cardiovascular risk in patients who go to the medical office will be found. In section III, it will find the results of the data collected for the measurement, as well as the most relevant values of the CVR found. In section IV, the discussion of the research work and finally in section $\mathrm{V}$, the conclusions, as well as the expectations that are had for the use of this research work.

\section{Methodology}

This section is made up of the process followed for the cardiovascular risk assessment, which are: data acquisition, data processing and finally the results with their corresponding risk values. The steps in carrying out the cardiovascular risk assessment are represented in a flowchart in Figure 1. All this was passed through the ethics committee, to give the authorization for the research work, followed by the ethical principles in part for the study in patients, such as beneficence, autonomy, nonmaleficence, and justice.

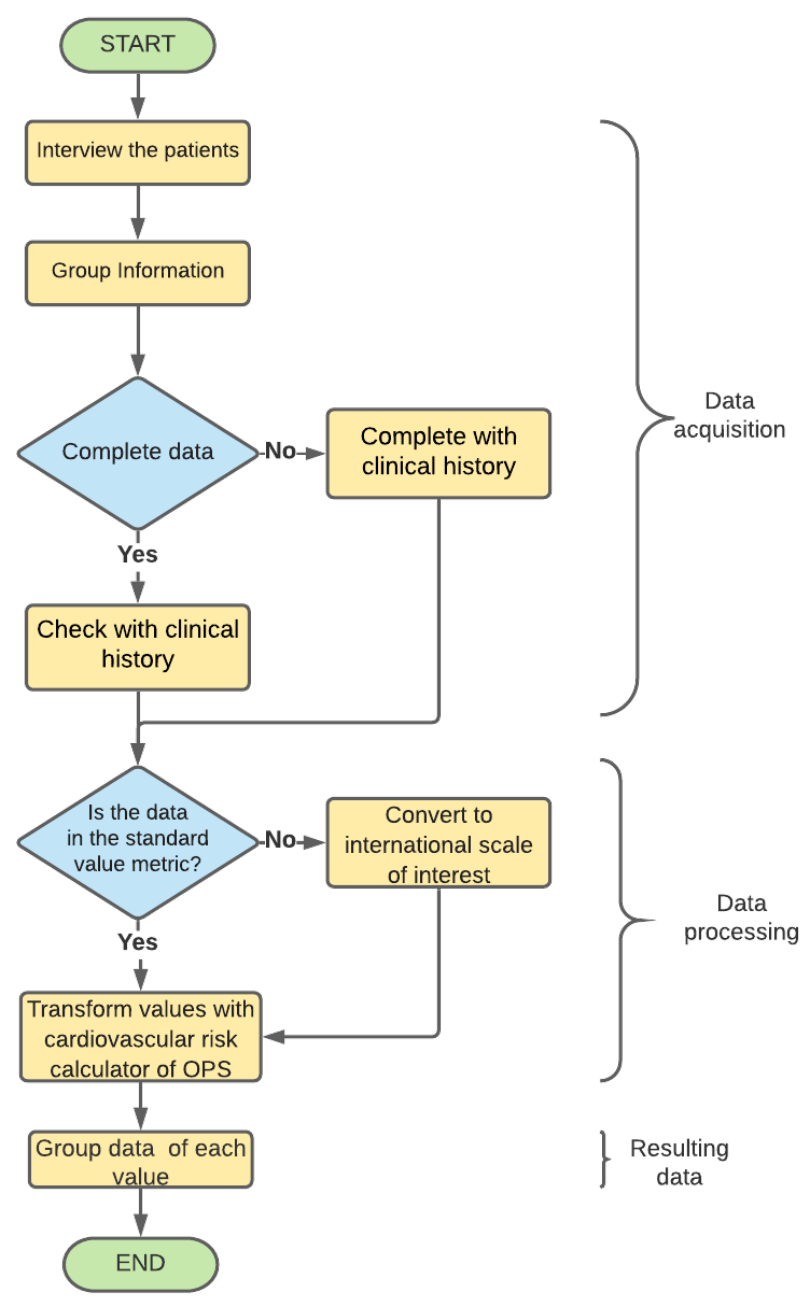

Figure 1: Flowchart for cardiovascular risk data collection

\subsection{Data Acquisition}

This study has a quantitative, non-experimental, descriptive, and cross-sectional approach. For the acquisition of the data, coordination was required with a private polyclinic located in the jurisdiction of North Lima, in which the patients of the cardiology service were evaluated in the first quarter of the year. Likewise, the data collected in the research work was cataloged in 
sociodemographic data of the patient and descriptive parameters of cardiovascular risk, the subdivisions are shown in Table 1.

Table 1: Sociodemographic data and descriptive parameters of cardiovascular risk of people from a cardiology clinic of a Private Polyclinic in North Lima

\begin{tabular}{|l|c|}
\hline \multirow{4}{*}{ Sociodemographic Data } & Gender \\
\cline { 2 - 2 } & Degree of instruction \\
\cline { 2 - 2 } Descriptive parameters \\
\begin{tabular}{l} 
of cardiovascular risk \\
\cline { 2 - 2 }
\end{tabular} & Occupation \\
\cline { 2 - 2 } & Taximum / Systolic Pressure \\
\cline { 2 - 2 } & Smoking \\
\cline { 2 - 2 } & Diabetes \\
\hline
\end{tabular}

\section{Population and Sample}

The population is made up of 110 adult patients (49-59) and older adults (60 or more) from the jurisdiction of the health center, but the sample size was made reaching 99 since the remaining patients did not want to participate voluntarily in the study.

\section{Inclusion and Exclusion Criteria}

The inclusion criteria that were considered at the time of data collection were: Patients who are between the ages of 49 and 79, who have high blood pressure, who are continuing or go to medical office more than once, who belong to the jurisdiction of the polyclinic and agree to participate voluntarily in the study.

In addition, the exclusion criteria corresponding to the study were: patients who depended on a wheelchair for mobilization and those who suffered from cognitive or hearing impairment.

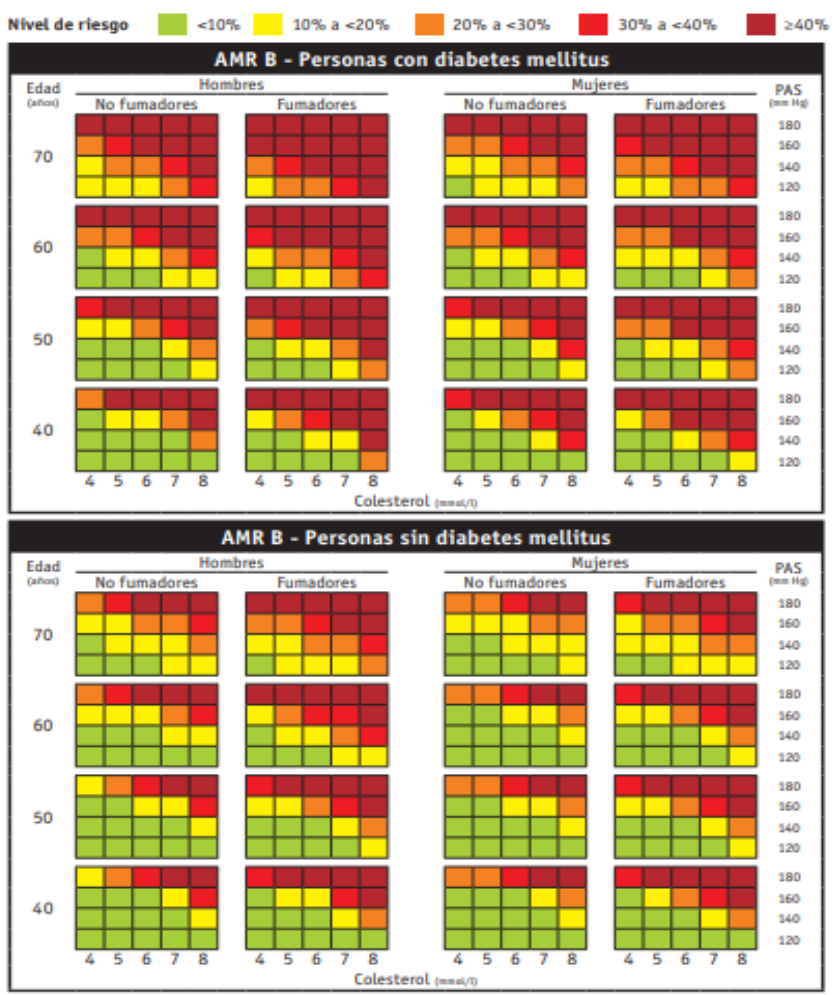

Figure 2: WHO/ISH AMR B risk prediction table, for settings in which blood cholesterol can be measured

\subsection{Data Processing}

The data corresponding to the descriptive parameters of cardiovascular risk were transformed into the international system of measurement units that were adequate or preferable for the measurement of each parameter and subsequently entered the cardiovascular risk calculator provided by PAHO that takes place during the month of November. These data were cataloged by the calculator according to the percentage of CVR of the patient suffering from a cardiovascular condition in the subsequent 10 years corresponding to the table displayed in Figure 2.

The table displayed in Figure 2 subdivides cardiovascular risk into 5 subsectors, relating them to one color according to the range of cardiovascular risk that occurs, these being: green, for a CVR $<10 \%$, yellow for a CVR from $10 \%$ to $<20 \%$, orange from $20 \%$ to $<30 \%$, red from $30 \%$ to $<40 \%$ and dark red for values $>40 \%$.

Likewise, the acquired data were entered in matrix form to the IBM SPSS Statistics 25 software, for subsequent management and analysis. The variables considered for data analysis are ID, gender, degree of institution, family type, occupation, smoking, diabetes, maximum systolic pressure, total cholesterol, cardiovascular risk, age, and Age 2, these two being the last ages corresponding to the adult and older adult age groups.

The participation of health personnel in the process of obtaining data is significant due to the complications that may arise due to the patient's lack of knowledge regarding the topic corresponding to each variable, the patient's mistrust of a person who do not work in the public health service, as well as greater efficiency in the collection of data in the clinical history and in the reliability when measuring the value of blood pressure.

\section{Results}

99 adult and elderly patients from the cardiology service were evaluated in the first quarter of the year. Sociodemographic data and descriptive parameters of cardiovascular risk were identified in each of them, as shown in Tables 2, 3 and 4.

Table 2: Sociodemographic data of patients from a cardiology clinic of a Private Polyclinic in North Lima

\begin{tabular}{|l|l|l|}
\hline Sociodemographic data & N & \% \\
\hline Age $^{1 /}$ & 57 & $57.6 \%$ \\
\hline Adult & 42 & $42.4 \%$ \\
\hline Older adult & \multicolumn{2}{|l|}{} \\
\hline Gender & 35 & $35.4 \%$ \\
\hline Female & 64 & $64.6 \%$ \\
\hline Male & 2 & $2.0 \%$ \\
\hline Degree of instruction & 16 & $16.2 \%$ \\
\hline Illiterate & 73 & $73.7 \%$ \\
\hline Primary & 5 & $5.1 \%$ \\
\hline Secondary & 3 & $3.0 \%$ \\
\hline Technical & \multicolumn{2}{|l}{} \\
\hline University & 17 & $17.2 \%$ \\
\hline Occupation & 10 & $10.1 \%$ \\
\hline Does not work & 12 & $12.1 \%$ \\
\hline Retired & \multicolumn{2}{|l}{} \\
\hline Laborer &
\end{tabular}




\begin{tabular}{|l|l|l|}
\hline Employee & 15 & $15.2 \%$ \\
\hline Informal work & 45 & $45.5 \%$ \\
\hline Total & $\mathbf{9 9}$ & $\mathbf{1 0 0 . 0 \%}$ \\
\hline
\end{tabular}

${ }^{1 /}$ Mean $=57.7 ;$ Standard Deviation $(\mathrm{SD})=11.08$

These results indicate that the mean age of the patients was 57.7 years, the majority being adults representing $57.6 \%$, likewise, $64.6 \%$ were men, $73.7 \%$ had a secondary level, $45.5 \%$ worked informally and $35.4 \%$ have an extended family as shown in Table 2.

Table 3: Cardiovascular risk parameters in patients of a cardiology office of a Private Polyclinic in North Lima

\begin{tabular}{|l|c|c|}
\hline Cardiovascular risk parameters & \multicolumn{2}{|c|}{$\square \pm$ SD $^{\mathbf{1 /}}$} \\
\hline Maximum Systolic Pressure (mmHg) & 132.9 & 11.6 \\
\hline Total Cholesterol (mg/dL) & 225.6 & 22.4 \\
\hline Smoking & $\mathbf{N}$ & $\mathbf{\%}$ \\
\hline Yes & 52 & $52.5 \%$ \\
\hline No & 47 & $47.5 \%$ \\
\hline Diabetes & & \\
\hline Yes & 84 & $84.8 \%$ \\
\hline No & 15 & $15.2 \%$ \\
\hline
\end{tabular}

${ }^{1 /}$ Mean ( $\square$ ); Standard Deviation (SD)

Table 3 shows that the mean maximum systolic pressure was $132.9 \mathrm{mmHg}$, and the mean total cholesterol was $225.6 \mathrm{mg} / \mathrm{d}$. On the other hand, $52.5 \%$ were smokers and $84.8 \%$ had diabetes.

Table 4: Cardiovascular risk and descriptive parameters of cardiovascular risk

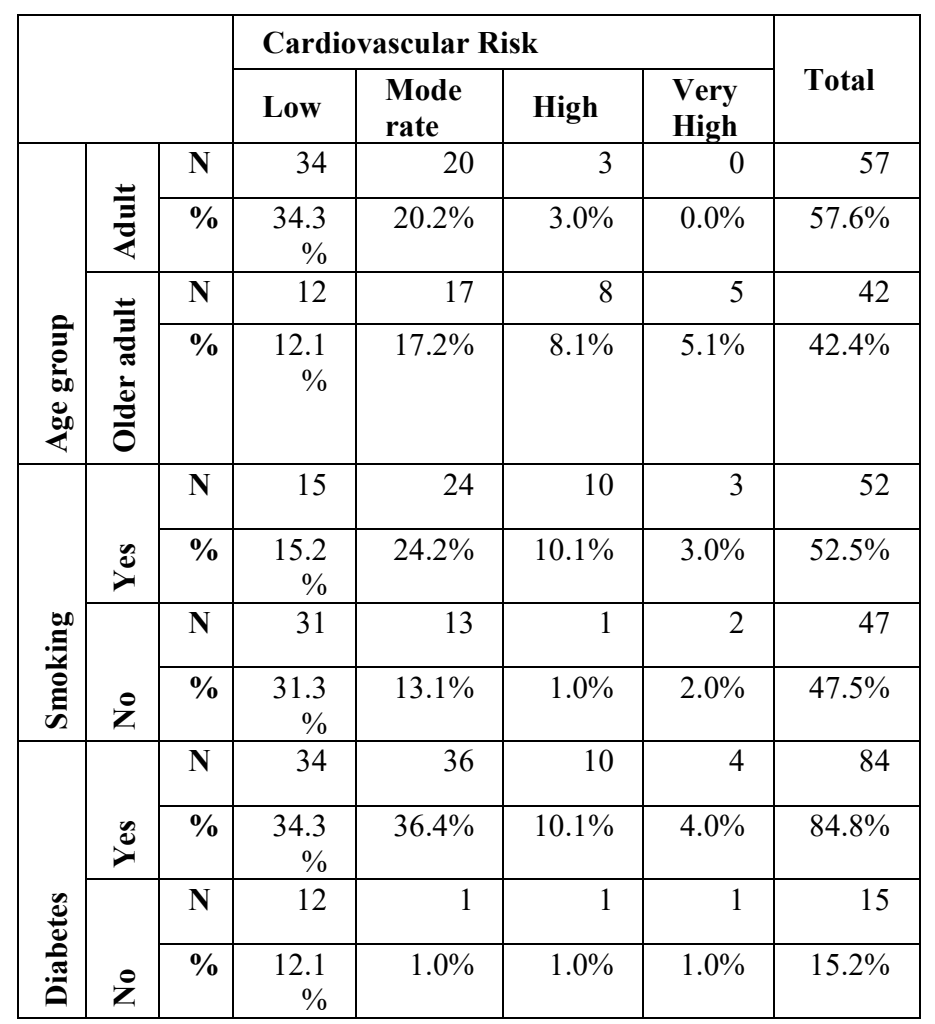

Table 4 shows that: adults are $57.6 \%$, with $34.3 \%$ belonging to a low CVR, while older adults are $42.4 \%$, and their CVR is mostly moderate with $17.2 \%$; those who smoke make up $52.5 \%$ of the population, their CVR being mostly moderate with $24.2 \%$, while those who do not smoke make up $47.5 \%$ and their CVR is mostly low with $31.3 \%$; finally, those with diabetes make up $84.8 \%$ of the population and their CVR tends to be moderate with $36.4 \%$ or low being $34.3 \%$, while those without diabetes make up $15.2 \%$ and most of them have a low CVR representing the $12.1 \%$. These data help to deduce the trend of cardiovascular risk in relation to its risk factors in private health center.

On the other hand, the chi square results were 0.001 for the age group and cardiovascular risk, 0.027 for diabetes and cardiovascular risk, and 0.001 for smoking and cardiovascular risk for $\mathrm{P}<0.05$, confirming that the differences in the proportions observed between the two groups are statistically significant. These results allow to identify the relationship of risk factors with cardiovascular risk in populations that go to a private health center, as well as to differentiate their situation from the current situation in Peru.

Table 5: Cardiovascular risk in patients of a cardiology office of a Private Polyclinic in North Lima

\begin{tabular}{|l|c|c|}
\hline Cardiovascular Risk & N & \% \\
\hline Extremely high Risk & 5 & $5.1 \%$ \\
\hline High Risk & 11 & $11.1 \%$ \\
\hline Moderate Risk & 37 & $37.4 \%$ \\
\hline Low Risk & 46 & $46.5 \%$ \\
\hline Total & $\mathbf{9 9}$ & $\mathbf{1 0 0 . 0 \%}$ \\
\hline
\end{tabular}

Table 5 shows that $46.5 \%$ of adult and elderly patients presented a low cardiovascular risk, $37.4 \%$ a moderate risk, $11.1 \%$ a high risk and $5.1 \%$ an extremely high risk.

The knowledge of these results is important because it will allow to identify cardiovascular risk in patients with no prior history of CVD, and it also helps to know the risk factors to which many people, such as smokers, are exposed. This information allows to realize that the greater control there is over risk factors, whether through a change in lifestyle (healthy eating, playing sports, etc.), the less likely there is to have cardiovascular risk.

\section{Discussion}

The results confirm that there is a significant relationship between smoking, age group and diabetes with cardiovascular risk, thus agreeing with the findings of the Framingham heart study.

On the other hand, the prevalence of CVR found is mostly belonging to a low-risk one, in other words, a population that has a less than $10 \%$ risk of suffering cardiovascular disease in the next 10 years, which contrasts significantly with the analysis carried out in [12], which lists circulatory diseases as the third cause of death for large groups and cardiac ischemia as the second cause of death. As it is a private health center, it can indicate a greater emphasis on prevention by a sector of the population with higher economic incomes.

Peru is a developing country where child malnutrition and respiratory diseases are still considered highly relevant problems and their financing is a high priority. For this reason, this research is not only focused on identifying the status of patients entering 629 
cardiology offices, but also on the scientific contribution, because its use is also expected to promote the use of this instrument for the early recruitment of patients, both by health personnel and residents through self-evaluation, because due to its easy access and simplicity it can mean a great advance for the prevention of cardiovascular diseases, in a country where, as declared in [13], self-knowledge, adherence or control of hypertension are still below to other Latin American countries.

\section{Conclusions}

It is concluded that in patients who go to the medical office of the private health center in North Lima, diabetes, smoking and the age group are predisposing factors to increased cardiovascular risk in patients.

It is also concluded that the majority were adults, with a secondary institution degree and who work informally. As well as 5 out of 10 patients were smokers and 8 out of 10 had diabetes.

Finally, it is concluded that cardiovascular diseases are made up of a series of characteristics that can be regulated to prevent a cardiovascular risk, such as smoking, diabetes, total cholesterol, and maximum systolic pressure. As well as that the problem increases in relation to the old age of the population and therefore measures should be taken focused on these age groups.

This research work was studied to contribute to the lack of scientific information with the use of the PAHO cardiovascular risk calculator, in addition to promoting its use in the Peruvian community nursing setting for the recruitment of risk patients, because despite having problems such as malnutrition in the child population, the obstacle that CVDs pose to life expectancy in adults and older adults cannot be ignored.

The Strength in our research work is teamwork to be able to carry out this research work

The limitation in the research work is access to people to be in the study, since many of them mentioned that they preferred to enter their consultations than to be in the study.

\section{Conflicts of Interest}

The authors declare no conflict of interest.

\section{References}

[1] M. Arboleda, A. García, "Riesgo cardiovascular: análisis basado en las tablas de Framingham en pacientes asistidos en la unidad ambulatoria 309, IESS Sucúa,” Revista Med, 25(1), 20-30, 2017, doi:10.18359/rmed.1949.

[2] J. Álvarez, A. Álvarez, W. Carvajal, M. González, J. Duque, O. Nieto, "Determinación del riesgo cardiovascular en una población.," Revista Colombiana de Cardiologia, 24(4), 334-341, 2017, doi:10.1016/j.recar.2016.08.002.

[3] R. D’Agostino, R. Vasan, M. Pencina, P. Wolf, M. Cobain, J. Massaro, W. Kannel, "General cardiovascular risk profile for use in primary care: The Framingham heart study," Circulation, 117(6), 743-753, 2008, doi:10.1161/CIRCULATIONAHA.107.699579.

[4] J. Alvarez, V. Bello, G. Pérez, O. Antomarchi, M. Bolívar, "Factores de riesgo coronarios asociados al infarto agudo del miocardio en el adulto mayor.," Medisan, 17(1), 54-60, 2013.

[5] Instituto Nacional de Estadistica e Informática, Peru, Enfermedades No Transmisibles Y Transmisibles, 2018.

[6] N. Atamari, M. Ccorahua, A. Taype, C. Mejia, "Mortalidad atribuida a diabetes mellitus registrada en el Ministerio de Salud de Perú, 2005-2014," Revista Panamericana de Salud Pública, 42, 1-7, 2018, doi:10.26633/rpsp.2018.50.

[7] K. Adams, J. Chirinos, "Prevalencia de factores de riesgo para Síndrome
Metabólico y sus componentes en usuarios de comedores populares en un distrito de Lima, Perú," Revista Peruana de Medicina Experimental y Salud Publica, 35(1), 39-45, 2018, doi:10.17843/rpmesp.2018.351.3598.

[8] J. Mayta, A. Morales, A. Cárdenas, J. Mogollón, V. Armas, L. Neyra, C. Ruíz, "Determinación de riesgo cardiovascular y edad vascular según el score de Framingham en pacientes del Hospital Nacional Arzobispo Loayza," Horizonte Med, 15(2), 27-34, 2015, doi:10.1520/stp30190s.

[9] A. Sánchez, M. Bobadilla, B. Dimas, M. Gómez, G. González, "Enfermedad cardiovascular: primera causa de morbilidad en un hospital de tercer nivel.," Revista Médica de Cardiologia, 27(3), 98-102, 2016.

[10] C. Torres, D. Illera, D. Acevedo, M. Cadena, L. Meneses, P. Ordoñez, L. Pantoja, M. Pastás, "Riesgo cardiovascular en una población adolescente de Timbío, Colombia," Revista de La Universidad Industrial de Santander. Salud, 50(1), 59-66, 2018, doi:10.18273/revsal.v50n1-2018006.

[11] OPS/OMS, Calculadora de riesgo cardiovascular, Organización Panamericana de La Salud - Uruguay,

[12] Ministerio de la Salud, ASIS-R: Análisis de Situación de Salud de los Gobiernos Regionales, 120, 2019.

[13] P. Herrera, J. Pacheco, G. Valenzuela., G. Málaga, "Autoconocimiento, Adherencia al tratamiento y control de la Hipertensión Arterial en el Perú: una versión narrativa.," Revista Peruana de Medicina Experimental y Salud Publica, 34(3), 497-504, 2017, doi:10.17843/rpmesp.2017.343.2622. 